\title{
THE POLITICAL CONTEXT OF RESEARCH INFRASTRUCTURES: CONSEQUENCES FOR IMPACT AND EVALUATION ${ }^{1}$
}

ISABELLE VAN ELZAKKER AND LEONIE VAN DROOGE DOI: 10.22163/fteval.2019.342

\section{ABSTRACT}

$\mathrm{R}$ esearch Infrastructures (RIs) face big expectations regarding their societal impact. As a consequence, there is a need for methods to monitor and assess impact. But expectations differ between funders, organisations and countries, they change overtime and they are not always clear. In addition, expectations often relate to other functions, roles or ideas of an infrastructure than that of an organisation that enables excellent research. It is clear that a standard set of impacts and indicators doesn't do justice to these differences. Yet, at the same time, there is a need for a harmonized approach to impact monitoring. In this paper we describe the development of such an approach for a consortium of Rls as part of the H2020 ACCELERATE project.

\section{INTRODUCTION}

Large Research infrastructures (Rls) have become an objective of a variety of policies, both on the regional and national, as well as the European level. Governments and public organisations across all these levels make large public investments to construct and operate Rls. Moreover, different countries and organisations are increasingly cooperating in funding and managing Rls. To legitimize these efforts, both funders and Rls themselves expect Rls to have various beneficial impacts, ranging from scientific breakthroughs to regional innovation and the development of new technologies.

The evaluation, as well as the governance of societal impact, is a challenge. There have been reports and studies of impact, yet there is no common agreement on impacts to expect, or approaches to evaluate impact. However, improved governance and evaluation of societal impacts is expected to contribute to the long term sustainability of Rls.

The context of this paper is the ACCELERATE project, dedicated to the long term sustainability of Rls in the field of materials research. The Rls have articulated the need for a proactive governance of societal

impact. The Rls indicated that the studies and methods available, do not respond to their needs. We are involved in the project in order to develop a societal impact approach for use by the Rls themselves. The paper addresses the question: How to understand societal impact of a Research Infrastructure?

In this paper we describe how the (European) Rl policy landscape developed in the past two decades. It is in the context of these broader developments that the question of societal impact is brought to the fore. We describe core elements of methods used for societal impact assessment of RIs. We relate this to the practice and needs of the Rls involved in the ACCELERATE project. In the discussion, we reflect on the implications of the political context in which Rls operate, for the understanding of societal impact of Rls.

\section{BACKGROUND: DEVELOPMENT OF THE RI (POLICY) FIELD}

Since the turn of the century, Rls have gained a significant position on the European (science) policy agenda. The memorandum 'Towards a European Research Area', published and approved in 2000, positioned Rls as a policy objective on the agenda (European Commission, 2000). Rls are, according to the Memorandum, important for scientific progress. They are tools for European cooperation and integration. The notion of a European strategy for Rls that was introduced in the memorandum, offered individual member states the prospect of reducing costs, by sharing the capital and operational investments accompanying the establishment of Rls (Papon, 2004).

Research Infrastructures, according to the European Commission, are facilities, resources and services that are used by the research communities to conduct research and foster innovation in their fields. They include major scientific equipment or sets of instruments; knowledgebased resources such as collections, archives or scientific data; e-infrastructures such as data and computing systems and communication 
networks; and any other infrastructure of a unique nature essential to achieving excellence in research and innovation (European Commission, 2018a: part 4, p.5).

To enable the development of a European strategy on RIs, the European Strategy Forum on Research Infrastructures (ESFRI) was established in 2002. ESFRI aims to support a "coherent and strategy led approach to policymaking on research infrastructures" (ESFRI, 2018). One of the tools is roadmapping; a strategic, long-term, policy-relevant planning exercise between member states (OECD, 2008), resulting into roadmaps for the construction and development of pan-European research infrastructures. In 2006 ESFRI published its first roadmap and ESFRI has updated the roadmap multiple times since then. Each new roadmap includes new projects and initiatives, as well as projects from earlier roadmaps. What is on the roadmap is an RI.

The efforts to establish a coherent European RI strategy influences the national processes in its member states. ESFRI expects member states to develop their own national roadmaps. These need to include national facilities as well as participation in international Rls. In the Netherlands, for example, the national roadmap is harmonized with the European roadmap (NWO, 2016). This means that national Rls, or consortia of RIs, have to link to an international initiative on the ESFRI roadmap, to be eligible for a place on the national roadmap. A substantive amount of Dutch public funding for Ris is tied to the national roadmap. This financial incentive thus encourages national Rls to connect with pan-European RI initiatives.

Another development in the creation of a unified European RI landscape, is the introduction of the European Research Infrastructure Consortium (ERIC) legal framework (EC, 2009). The ERIC framework provides consortia the possibility to act as a European legal entity. The consortium can consist of - and is funded and governed by - EU Member States, associated countries, third countries and intergovernmental organisations. The ERIC framework provides a blueprint for a structure and it allows for a faster process than creating an international organisation. An ERIC needs to represent added-value in the development of the European Research Area (ERA). It needs to contribute to significant improvement in the relevant scientific and technological fields, to the mobility of knowledge and/or researchers within the ERA and to the dissemination and optimisation of results (EC, 2018b).

In the past two decades, the number and variety of facilities that are identified as Rls and that are included on roadmaps have grown. Currently, a large variety of facilities is identified as an RI: from single sited physical buildings with equipment for scientific experiments and measurements to distributed testbeds for crops and from virtual and networked datasets for social sciences and humanities research to mobile facilities for marine research.

\section{"LONG TERM SUSTAINABILITY" AND SOCIETAL IMPACT}

The long term sustainability of Research Infrastructures has received attention in recent years. The Conclusions of the Council of the European Union in 2016 underlined the importance and urged the European Commission to develop an action plan. In response, ESFRI established the Long-term Sustainability Group. The OECD as well as various H2O2O projects address the issue. The lifecycle of a RI often covers multiple de- cades. To ensure the sustainability of a RI throughout its lifecycle, ESFRI identified different aspects and issues concerning sustainability (ESFRI 2017). They include the effective governance of Rls, the (lack of) coordination between the national and European level, and the availability of people with the right skills and experience.

One of the obstacles for ensuring the long term sustainability of Rls is the lack of a sound methodology for identifying and assessing the societal impact of Rls. Some Rls require substantive public investments. The expectations driving these investments have shifted in the past decades and Rls. Even Rls that do not require such investments are now expected to contribute to the needs of contemporary society (Hallonsten, 2017). As a consequence, there is political and social pressure to identify, monitor and evaluate the contribution that RIs make to society in general, or to regional and national economies, or through the science the Rls deliver, such as better healthcare, a cleaner environment or developments to communications and transport (ESFRI, 2017). However, clear articulation of expectations regarding societal impact, or regular monitoring, are not yet common practice, neither among funders, members and stakeholders, nor at RIs (ESFRI, 2017). Still, the need to develop a standard methodology for assessing the societal impact of Rls is widely shared (cf. European Commission (2017), OECD (2017), ESFRI (2017)).

\section{THE SOCIETAL IMPACT OF RESEARCH INFRASTRUCTURES}

Despite the call for a methodology, there is no lack of studies dedicated to the societal impact of Rls. They cover a broad range of methods, from ex-post qualitative case studies, to ex-ante cost-benefit analyses (Giffoni et al, 2018b). Most focus on a specific RI (e.g. on ISIS (Simmonds, 2016), European Social Survey (Kolarz, 2017) and ICOS ERIC (Van Belle et al, 2018)), but there have been attempts to develop a more generic framework for the assessment of societal impacts as well. Examples include the work of Technopolis (Greniece et al, 2015), the FenRIAM guide (Roschow et al, 2014), the ongoing work of the OECD Global Science Forum (OECD, 2017; OECD, 2018) and the recently started H2020 project RI-PATHS.

There are similarities between the studies, such as the use of a model for impact - or of elements such as inputs, activities, outputs, outcomes and impacts. Another similarity is the articulation of the differences between Rls, including in studies dedicated to a specific RI. Yet the studies differ in how they analytically "pull apart" impact and Rls. The questions "impact of what?" and "impact on what?" are addressed in different ways.

\section{DATA}

We have used desk research to study the evolving policy context of RIs. We focused on policy documents concerning RIs, the ERA and roadmaps, as well as policy documents addressing societal impact (assessment) of Rls. We studied literature on RI impact, including consultancy reports and case studies. Through our project, we had access to official as well as internal documents of the member Rls, including Statutes and Annual Reports, as well as monitoring documents.

We interviewed representatives of the Rls involved in ACCELERATE and organised joint workshops to identify questions, interests and needs regar- 
ding impact, to identify relevant stakeholders that are involved in the evaluation of societal impact, as well as to discuss expectations and practices.

Finally, we have been involved and invited in a number of meetings regarding societal impact of Rls. This helped us relate our project to ongoing developments in the field of societal impact of Rls.

\section{RESULTS - WHAT IMPACT AND IMPACT OF WHAT?}

The studies of and reports on societal impact of Rls use different interpretations of impact and Rls. We describe three common trends. We then use these interpretations to describe the Rls of the ACCELERATE project.

\section{IMPACT OF WHAT}

Some studies use observable characteristics of an $\mathrm{Rl}$ as a starting point. For example the scientific domain or discipline the RI serves, its scope (single-sited, distributed, mobile or virtual) or phase (construction, operation, decommissioning) (ESFRI, 2017). RI PATHS proposes a more holistic approach, where the taxonomy is based on type of research (Giffoni et al, 2018a). Technopolis uses a typology of characteristics that makes the phase explicit (Technopolis, 2015).

\section{IMPACT ON WHAT}

Some of these studies propose a typology of impacts as well. Technopolis (Greniece, 2015) distinguishes between impacts on the economy, on innovation, on human resource capacity and on society.

\section{IMPACT AS A CONTRIBUTION TO A GOAL}

More recent impact studies (Kolarz et al. 2017), policy documents (ESFRI 2017, OECD, 2018) and impact approaches developed by Rls themselves (ESS, 2018), use a different approach. They relate impact to other features of the Rls. They state that a one-size-fits-all approach will not do, and that "there seems to be no "silver bullet" for capturing the impacts of RI" (Berger et al, 2018: 55), precisely given the heterogeneity of Rls and of impacts. They relate societal impact to the objectives or goals of a specific RI (ESS, 2018). Some include that impact also relates to expectations of stakeholders (OECD, 2018: 1), since Rls face multiple stakeholders, that have different strategic visions and expectations. Studies relate impact to goals, missions and expectations. Impact can be understood as a "contribution to".

\section{THE ACCELERATE RIS}

The ACCELERATE consortium consists of five RIs: CERIC (Central European Research Infrastructure Consortium), ESS (the European Spallation Source ERIC), FRM II, HZG-GEMS (Helmholtz Gesellschaft) and ELI (Extreme Light Infrastructure). They are all dedicated to enabling materials research: the characterisation of matter, from subatomic to supramolecular scale. The research that the Rls enable is done with equipment called beamlines or instruments. These are connected to a powerful source, an accelerator, spallation source, or laser.

\section{IMPACT OF WHAT?}

The members can be further described using some basic characteristics:

Phase: ELI is currently under construction. It will enable materials research in the future, however at present it is a building project. FRM II is in operation since 2015.

Scope: FRM II is a single sited RI. The research facility is located on one specific site, in Garching, Germany. The spallation source of ESS is built on a single site in Lund, Sweden. However the Data Management and Software Centre (DMSC) is located in Copenhagen, Denmark. In the other cases, the RI consists of multiple physical sites that together make up the RI. HZG-GEMS manages instrumentation at different sites, ELI consists of three research facilities and CERIC coordinates between a number of facilities.

Governance: Three of the RIS, ELI, ESS and CERIC, are ERICs. This means that they have a European legal status. They are governed by European countries that are a member of the ERIC, and that fund part of its construction/operation, either in-kind or in cash. In contrast, the two German Rls are part of existing research organisations: FRM II is governed by Technical University Munich and HZG-GEMS that operates instruments at distant facilities, is operated by the Institute for Materials Research, which is part of the Helmholtz Gesellschaft. The latter two are funded through national and regional scientific funds.

Span of control: With span of control we refer to the responsibilities and possibilities of the $\mathrm{RI}$ regarding the facilities it offers access to. CERIC does not own any physical instrument, beamline or source; it offers access to beamlines operated by representatives of the member states, at different partner facilities. On the other hand, FRM II manages both source, as well as part of the instruments. FRM II both facilitates research as well as does in house research and it is a source of medical isotopes.

\section{IMPACT ON WHAT}

All ERICs (CERIC, ESS and ELI) need to represent added-value in the development of the European Research Area. The ERA focuses on five key priorities. The ERICs are expected to report on their contribution to these priorities. The priorities are negotiated by different political actors within the EU. They can change overtime in a response to new issues arising or others becoming less relevant.

In some Rls, the statutes provide some information on what they should impact on. CERIC- ERIC's objective shall be to "stimulat [e]... beneficial impact on the scientific, industrial and economic development. (CERIC 2014: 6) and CERIC "shall proceed to the periodical evaluation of [...] its impact on the European Research Area, on the Regions hosting its Partner Facilities and at international level. " (CERIC 2014: 12)

\section{IMPACT AS A CONTRIBUTION TO A GOAL}

Some members have defined contributions to goals These (strategic) goals are used as, in other words to define, impact categories.

ESS for example, uses their strategic goals as impact categories: (1) World-Class RI Enabling Scientific Breakthroughs and Addressing Grand Societal Challenges (2) Supports and Develops Its User Community, Fosters a Scientific Culture of Excellence and Acts as an International Scientific Hub. (3) Is Built on Time and on Budget, Operates Safely, Efficiently 
and Economically, and Responds to the Needs of Stakeholders and (4) Develop Innovative Ways of Working (ESS, 2018).

\section{DISCUSSION AND CONCLUSIONS}

We discuss the above in the context of the experiences and needs of the members of ACCELERATE. They require an approach, or an understanding of societal impact, that improves the possibility to pro-actively govern impact. These Rls, just as others, face a complex stakeholder community, consisting of their members, funders, users and beneficiaries; each with different expectations regarding societal impact, each with different requirements, and each with a different interpretation of impact, if any.

The members of ACCELERATE are all dedicated to enabling materials research by providing access to instruments and beamlines. Apart from these similarities the Rls differ considerably: from building projects to up-and-running organisations; from institutionally or nationally governed organizations to former EU project consortia turned ERICs, funded by member states; from an annual budget of 3 million euro to an 1.8 billion euro investment. It is evident that the impacts will differ given these characteristics, and that different impacts are expected given the different stakeholder communities. At the same time, supranational European initiatives call for coherent policies for Rls, including for the (assessment of) societal impact of Rls. There is an inherent tension here, given the different characteristics and contexts.

The ACCELERATE members are expected to have an impact on the economy, innovation and other societal sectors, as well as on the societal challenges. Yet these expectations are in most cases not concrete or specific. It is often unclear to the Rls what is expected in terms of the nature of the impact, the contribution by the RI or the evidence of impact. Regarding the impact on ERA priorities, for instance, the ERICs merely contribute to. This is in line with the more recent development, where impacts relate to objectives. As mentioned above, one of the members has developed a societal impact approach that uses its strategic objectives as impact categories.

However, the ACCELERATE members report that there is more to impact than is formally agreed and communicated in statutes, mission statements and strategic objectives. Different stakeholder groups have different perspectives of what an $\mathrm{Rl}$ is. For a hosting member country, the seat of an ERIC is a prestigious project; for the ministry of economic affairs of a member country, the same Rl is an opportunity for high-tech industry; for a ministry of science, the very same $\mathrm{Rl}$ is the opportunity to collaborate with excellent scientists from abroad. For a regional government, the $\mathrm{Rl}$ is a high-tech employer; the reactor of that $\mathrm{Rl}$ is perceived by some of the local population as a potential danger; for doctors and patients in a different country, the $\mathrm{Rl}$ is a provider of medical isotopes.

Every stakeholder seems to have a different perception of an RI. And each perception relates to a different impact or contribution. Pro-active governance of societal impact includes pro-active governance of the image or perception the stakeholder has of an RI. What an RI does, or what it monitors, depends not only on the impact expected, but also on the perception of a stakeholder, and the $\mathrm{Rl}$, what the $\mathrm{Rl}$ is.

These perceptions are not just "out there"; what an Rl is, and what impact to expect, can be discussed and negotiated between the RI and its stakeholders, and among different stakeholders. An Rl is in that sense a boundary object (Star and Griesemer, 1989). It is adaptable to view- points of a wide variety of stakeholders including stakeholders that are not commonly involved in science and innovation, such as local communities and regional employers. What a Research Infrastructure is, is influenced by the perception and expectations of the stakeholder, the activities and strategy of the RI as well as the negotiations, or the lack thereof, between these actors.

$\mathrm{An} \mathrm{Rl}$ is as a boundary object from another viewpoint as well. Policies regarding Rls have opened up possibilities and opportunities to include, develop or identify facilities as Research Infrastructure or in other words: to put them on the map. What is commonly referred to as a Research Infrastructure has been negotiated, expanded and stretched resulting into a large variety of projects and activities that are nowadays identified as an $\mathrm{Rl}$.

Revisiting current initiatives and practices in assessing societal impact and relating that to the practice of a number of Rls, aids in understanding the challenge regarding societal impact. The diversity of RIs, the large variety of stakeholders of an Rl and the different views they have about an $\mathrm{Rl}$, suggests indeed that a standard taxonomy, or a standard set of indicators, does not do justice. However, it does provide a direction. It starts from the observation that an $\mathrm{Rl}$ operates in a complex context, and that it is perceived differently by different stakeholders. Both Rls as well as stakeholders search for points of reference. This searching provides the opportunity to develop a joint view on what the RI is, and what can be expected of it.

\section{REFERENCES}

ACCELERATE (2018). Retrieved October 11th, 2018 from http://www. accelerate2020.eu/

Berger, F. et al. (2018). International Comparative Study: Appraisal and Evaluation Practices of Science Capital Spending on Research Infrastructures. Final Report. Brighton: Technopolis Group

BrightnESS (2018). private communication

CERIC (2014). STATUTES OF CERIC-ERIC. 24 June 2014 Decision no. 2014 2014/392/EU.

ESFRI (2018). Retrieved October 2018 from https://www.esfri.eu/

European Commission (2000). Communications "Towards a European research area" COM (2000) 6 of 18.1.2000.

European Commission (2009). Council Regulation (EC) on the Community legal framework for a European Research Infrastructure Consortium (ERIC) No 723/2009 of 25 June 2009.

European Commission (2010). Communication from the Commission to the Council, the European Parliament, the Economic and Social Committee and the Committee of the Regions - Towards a European research area COM/2000/0006 final.

European Commission (2017). Sustainable European Research Infrastructures - A call for action. Commission Staff Working Document, SWD (2017) 323 final. Luxembourg: Publications Office of the European Union. 
European Commission (2018a). Horizon 2020: Work Programme 20182020. Part 4. European research infrastructures (including e-Infrastructures). European Commission Decision C(2018)4708 of 24 July 2018.

European Commission (2018b). retrieved October 21st, 2018 from http://ec.europa.eu/research/infrastructures/index.cfm?pg=eric

European Strategy Forum on Research Infrastructures (ESFRI) (2017). Long-Term Sustainability of Research Infrastructures. ESFRI SCRIPTA Volume II. Milan: Dipartimento di Fisica - Università degli Studi di Milano.

Giffoni, F. et al (2018a). Deliverable 3.1 - Working note on RI typology. Retrieved September 24, 2018 from https://ri-paths.eu/

Giffoni, F. et al (2018b). Task 3.2 State of play - literature review. Retrieved September 24, 2018 from https://ri-paths.eu/

Griniece, E. et al. (2015). Evaluating and Monitoring the Socio-Economic Impact of Investment in Research Infrastructures. Tallinn: Technopolis Group.

Hallonsten, 0. (2017). Big Science Transformed. Science, Politics and Organization in Europe and the United States. London: Palgrave Macmillan.

Kolarz, P. et al. (2017). Comparative impact study of the European Social Survey (ESS) ERIC. Final report. Brighton: Technopolis Group.

Netherlands Organisation for Scientific Research (NWO) (2016). National Roadmap Large-Scale Scientific Infrastructure. Den Haag: NWO.

OECD Global Science Forum (2008). Report on Roadmapping of Large Research Infrastructures. Paris: OECD.

OECD (2014). The Impacts of Large Research Infrastructures on Economic Innovation and on Society: Case Studies at CERN. Paris: OECD.

OECD (2017). "Strengthening the effectiveness and sustainability of international research infrastructures." OECD Science, Technology and Industry Policy Papers, No. 48.

OECD Global Science Forum (2018). Draft Assessment Framework Initial Consensus Indicators as of 13 March 2018. Paris: OECD.

Papon, P. (2004). European scientific cooperation and Research Infrastructures: Past tendencies and future prospects. Minerva. 42, pp. 61-76.

Roschow, R. et al. (2014). FenRIAM full guide. Proposal for a Foresightenriched Research Infrastructure Impact assessment Methodology. Retrieved September 9, 2017 from http://www.fenriam.eu/overview.html

Simmonds, P. et al (2016). ISIS Lifetime Impact Study. Volume 1 - Full Report, Technopolis Group.

Star, S.L. and Griesemer, J. (1989). Institutional Ecology, 'Translations' and Boundary Objects: Amateurs and Professionals in Berkeley's Museum of Vertebrate Zoology, 1907-39. Social Studies of Science. 19 (3), pp. 387-420.
Van Belle, J. et al. (2018). ICOS Impact Assessment Report. Amsterdam: Technopolis Group.

Zubascu, F. (2018). Are research infrastructures the answer to all our problems? Science Business Retrieved September 19, 2018 from: https:// sciencebusiness.net/news/are-research-infrastructures-answer-all-ourproblems

\section{AUTHORS}

\section{ISABELLE VAN ELZAKKER}

Rathenau Institute

Anna van Saksenlaan 51, 2593 HW The Hague (the Netherlands)

E: i.vanelzakker@rathenau.nl

\section{LEONIE VAN DROOGE}

Rathenau Institute

Anna van Saksenlaan 51, 2593 HW The Hague (the Netherlands) E: I.vandrooge@rathenau.nl
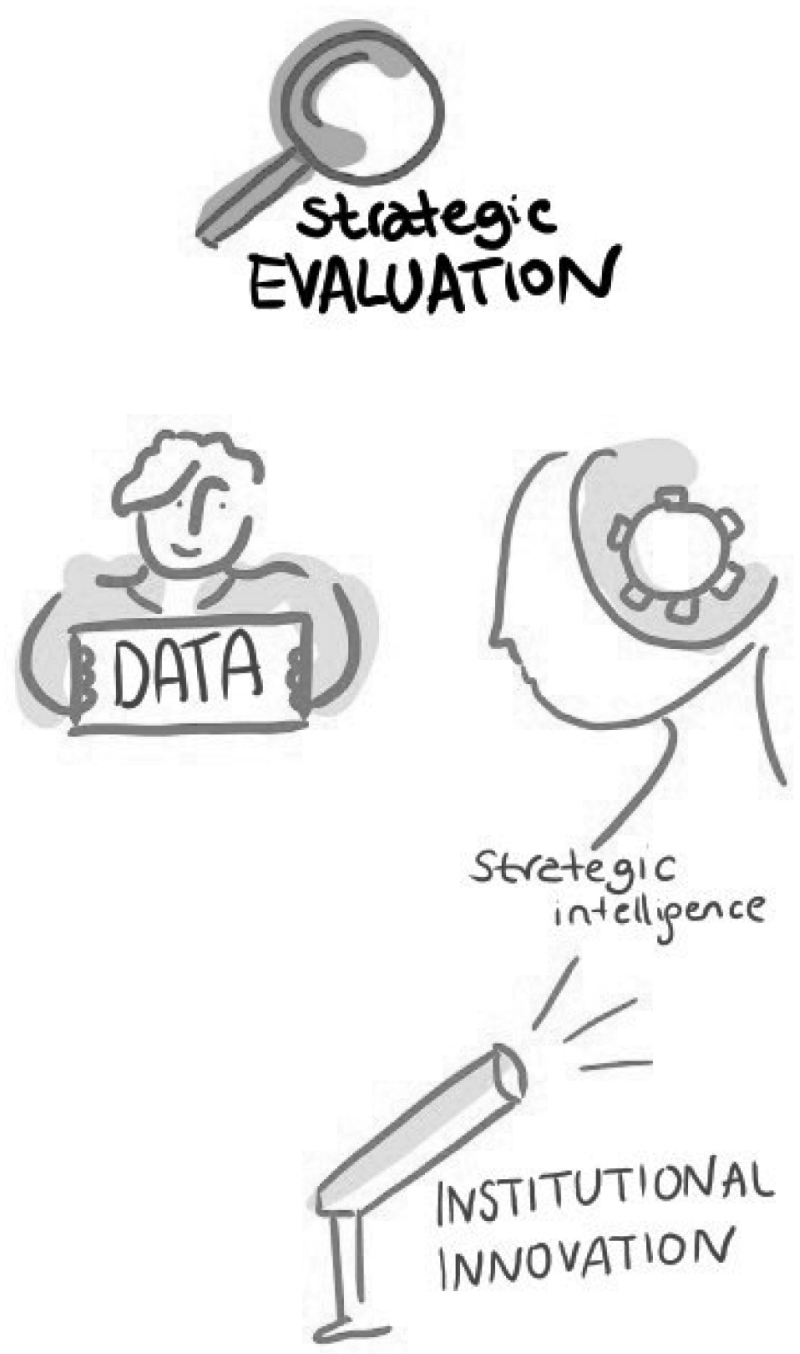